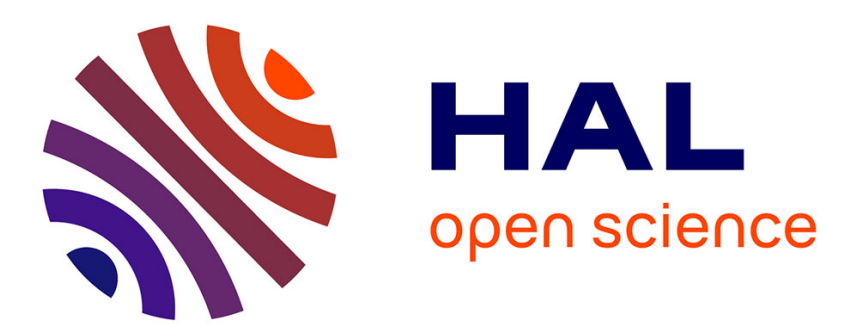

\title{
Maximal oxygen uptake and power of lower limbs during a competitive season in triathletes
}

Olivier Galy, Karim Chamari, Olivier Costes, Olivier Hue, Laurent Maïmoun, J. Manetta

\section{- To cite this version:}

Olivier Galy, Karim Chamari, Olivier Costes, Olivier Hue, Laurent Maïmoun, et al.. Maximal oxygen uptake and power of lower limbs during a competitive season in triathletes. Scandinavian Journal of Medicine and Science in Sports, 2003, 13 (3), pp.185-193. 10.1034/j.1600-0838.2003.10170.x . hal00720811

\section{HAL Id: hal-00720811 https://hal.univ-antilles.fr/hal-00720811}

Submitted on 25 Jul 2012

HAL is a multi-disciplinary open access archive for the deposit and dissemination of scientific research documents, whether they are published or not. The documents may come from teaching and research institutions in France or abroad, or from public or private research centers.
L'archive ouverte pluridisciplinaire HAL, est destinée au dépôt et à la diffusion de documents scientifiques de niveau recherche, publiés ou non, émanant des établissements d'enseignement et de recherche français ou étrangers, des laboratoires publics ou privés. 


\title{
Maximal oxygen uptake and power of lower limbs during a competitive season in triathletes
}

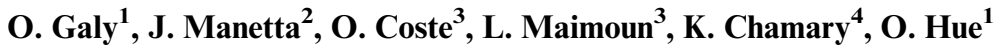 \\ ${ }^{1}$ Laboratoire ACTE, Unité de Formation et de Recherche des Sciences Techniques des Activités Physiques et Sportives, Antilles-Guyane, \\ Campus de Fouillole, 97159 Pointe à Pitre Cedex, France, ${ }^{2}$ Service de Physiologie Clinique, CERAMM, Center Hospitalier Universitaire, \\ 34295 Montpellier Cedex 5, France, ${ }^{3}$ Laboratoire de Physiologie des Interactions, Service Central de Physiologie Clinique, Unité \\ d'Exploration Respiratoire, Center Hospitalier Universitaire Arnaud de Villeneuve, 34295 Montpellier Cedex 5, France, ${ }^{4}$ Centre National \\ de la Médecine du Sport, Ave Mohamed Ali Akid, 1004 El Menzah, Tunisia \\ Corresponding author: Olivier Galy, UFR-STAPS Antilles-Guyane, 97159 Pointe à Pitre, France
}

Accepted for publication ?????? 2001

Background: In order to study the effect of a competitive triathlon season on maximal oxygen uptake $\left(\mathrm{VO}_{2 \max }\right)$, aerobic power (AeP) and anaerobic performance $(\mathrm{AnP})$ of the lower limbs, eight triathletes performed exercise tests after: (1) a pre-competition period (Pre-COMP) (2) a competitive period (COMP), and (3) a low (volume and intensity) training period (Post-COMP). The tests were a vertical jump-and-reach test and an incremental exercise test on a cycle ergometer. Ventilatory data were collected every minute during the incremental test with an automated breath-by-breath system and the heart-rate was monitored using a telemetric system. Results: No changes in $\mathrm{VO}_{2 \max }$ were observed, whereas AeP decreased after Post-COMP compared to Pre-COMP and COMP and AnP decreased during COMP compared to Pre-COMP and Post-COMP. In addition, second ventilatory threshold $\left(V^{2} T_{2}\right)$ and power output at first ventilatory threshold (VT1) and $V_{T_{2}}$ decreased after Post-COMP. Conclusion: This study showed that six weeks of low volume and intensity of training is too long a period to preserve adaptations to training, although a stable maximal oxygen uptake throughout the triathlon season was observed. Moreover, the AnP decrease during COMP was probably in relation with the repetitive nature of the training mode and/or triathlon competitions.
In endurance events, several factors have been demonstrated to be correlated with performance. These include maximal oxygen uptake $\left(\mathrm{VO}_{2 \mathrm{max}}\right)$, ventilatory thresholds, power (i.e., during cycling test) or velocity (i.e., during running test) developed at $\mathrm{VO}_{2 \max }$ and at ventilatory thresholds, running economy (RE) and maximal treadmill running performance (Conley \& Krahenbuhl, 1980; Morgan, Martin, Krahenbuhl, 1989; Noakes, Myburgh, Schall 1990; Billat \& Koralsztein, 1996; Paavolainen, Häkkinen, Hämäläinen, Nummela, Rusko, 1999). Explosive strength training is also important during aerobic activities, especially running (Paavolainen et al., 1999). Paavolainen et al. (1999) demonstrated that a specific nine week training program with simultaneous explosive strength and endurance training improved the fivekilometers run performance by improving RE and muscle power in well-trained athletes.

Other activities such as prolonged cycling and running or the triathlon decrease muscular strength after exercise (Hausswirth, Bigard, Guezennec, 1997; Lepers, Hausswirth, Mafiuletti, Brisswalter, Van Hoecke, 2000a,b). During a triathlon, the running segment is determinant to overall performance in today's races (Hue, Le Gallais, Chollet, Boussana, Préfaut, 1998; Millet, Millet, Hofmann, Candau, 2000). Changes in stride length and stride frequency are elicited, and these may be affected by changes in muscle properties (i.e., strength) (Hausswirth et al., 1997), as well as by an aptitude to maintain a high level of intensity (Hue, Le Gallais, Boussana, Chollet, Préfaut, 2000; Millet et al., 2000).

The anthropometric and physiological characteristics of triathletes have been well described, (Kohrt, Morgan, Bates, Skinner, 1987; Kreider, 1988; Roalstad, 1989) and both training volume (Laurenson, Fulcher, Korkia, 1993) and training intensity (Hue et al., 2000; Millet, Candau, Barbier, Busso, Rouillon, Chatard, 2002) influence the $\mathrm{VO}_{2 \max }$ and ventilatory thresholds in triathletes (Hue et al., 2000). However, within a competitive season, the variations in both aerobic (i.e., maximal oxygen uptake, ventilatory thresholds, power) and anaerobic performance remain unknown, even though these are widely considered to be determinant factors in performance (Paavolainen et al., 1999; Hue et al., 2000; Millet et al., 2000). 


\section{Galy et al.}

The aim of the present study was thus to investigate aerobic and anaerobic performance during a competitive season in highly trained triathletes in relation with training schedule (i.e., volume and intensity).

\section{Materials and methods}

\section{Subjects}

One female and seven male competitive triathletes participated in this study (age: $19.6 \pm 0.2$ years, body mass: $67.0 \pm 1.9 \mathrm{~kg}$, and height: $175.1 \pm 1.8 \mathrm{~cm})$. All were athletes of the Regional Center of Popular Education and Sports of Montpellier, France (Center Régional de l'Education Populaire et du Sport). Two of them were members of both the French Junior Team and the University Athletic Team. The others were nationally ranked and members of the Regional Junior Team and/or the University Athletic Team. All had been competing in the triathlon for $5.0 \pm 0.3$ years. All were non-smokers, had normal lung function, and gave no prior history of pulmonary or cardiovascular disease. Before the trials, the triathletes were familiarized with both the use of the cycle ergometer and the countermovement jump. All subjects gave informed written consent before participating in the protocol, which was in accordance with legal requirements and the Declaration of Helsinki, and was approved by the local ethics committee.

\section{Protocols}

All tests were conducted in an air-conditioned laboratory with a mean room temperature of $21.1 \pm 0.1^{\circ} \mathrm{C}$ and a barometric pressure of $777.3 \pm 4.8 \mathrm{mmHg}$. The tests were performed at the same time of day and on the same day of the week to minimize the effects of circadian rhythms and personal training. In addition, during the study period, they were also asked to refrain from training on experimental days. In the year preceding the study, the triathletes had agreed to follow a specific training schedule and to record their weekly training volume in swimming, cycling, running, and physical preparation, which is composed of specific exercises to improve abdominal muscle tone. They were trained daily by a professional coach who was specifically assigned to their group. The whole training year was divided into three periods: a pre-competition period (Pre-COMP) of 28 weeks with the first 16 weeks focused on high volume training in each triathlon component (i.e., swimming, cycling, and running) without triathlons and followed by 12 weeks of high volume training including progressive increase in intensity and specific multiblocks in cycling and running. The multiblock training consisted of repeated sessions of cycling and running consecutively in order to improve the specific phase of running after cycling in the triathlon (i.e., the cycle-run transition). A second competitive period (COMP) of 18 weeks emphasized high intensity training in each component and included approximately one triathlon every two weeks. A final post-competition period (Post-COMP) of six weeks was characterized by a large reduction in both training volume and intensity (Fig. 1), and triathletes were not allowed to compete. Table 1 presents a specific weekly training schedule for each period (Pre-COMP, COMP, Post-COMP) with specific times (X) dedicated to evaluating intensity or volume of training planned. Intensities were identified by three phases: (1) phase 1 or 'low intensity' $<$ to the $\mathrm{VT}_{1}$; (2) Phase 2 or 'moderate intensity' between $\mathrm{VT}_{1}$ and $\mathrm{VT}_{2}$; and (3) Phase 3 or 'high intensity' $>\mathrm{VT}_{2}$; according to Skinner and McLellian (1980). A high training volume was a schedule over $15 \mathrm{~h} /$ week. High intensity was a schedule of only phase 2 and phase 3 . Intensity was monitored by the triathletes with their own telemetry system (Polar Accurex plus, Polar Electro Oy, Kempele, Finland) and calculated from the results of $\mathrm{VO}_{2 \max }$. In addition, differences observed between fig. 1 and Table 1 in the volume of training are due to the difference between the planned training schedule and the training actually performed by the triathletes during the entire study year.

\section{Countermovement jump test}

The first trial consisted of a jump-and-reach test performed using an ergojump (Jump-MD, Takeï, Japan) adjusted to each triathlete's height. The subjects were asked to perform a countermovement jump in which they began in a standing position, dropped into the semi-squat position, and immediately jumped as high as possible. The jump height was given automatically by the ergojump. Three tests were performed with five minutes of rest between them. The best jump was used for analysis (Vandewalle, Peres, Monod, 1987). All measurements were made with a precision of one centimeter. This method allowed us to evaluate their anaerobic performance (AnP). The power output during the jump-and-reach test was determined by entering the jump height and body weight variables into the equation of Sayers, Harackiewicz, Harman, Frykman, Rosenstein (1999): Maximal power $(\mathrm{W})=51.9 \times \mathrm{CMJ}$ height $(\mathrm{cm})+48.9 \times$ body mass $(\mathrm{kg})-2007$, where CMJ height is the height attained during the countermovement jump.

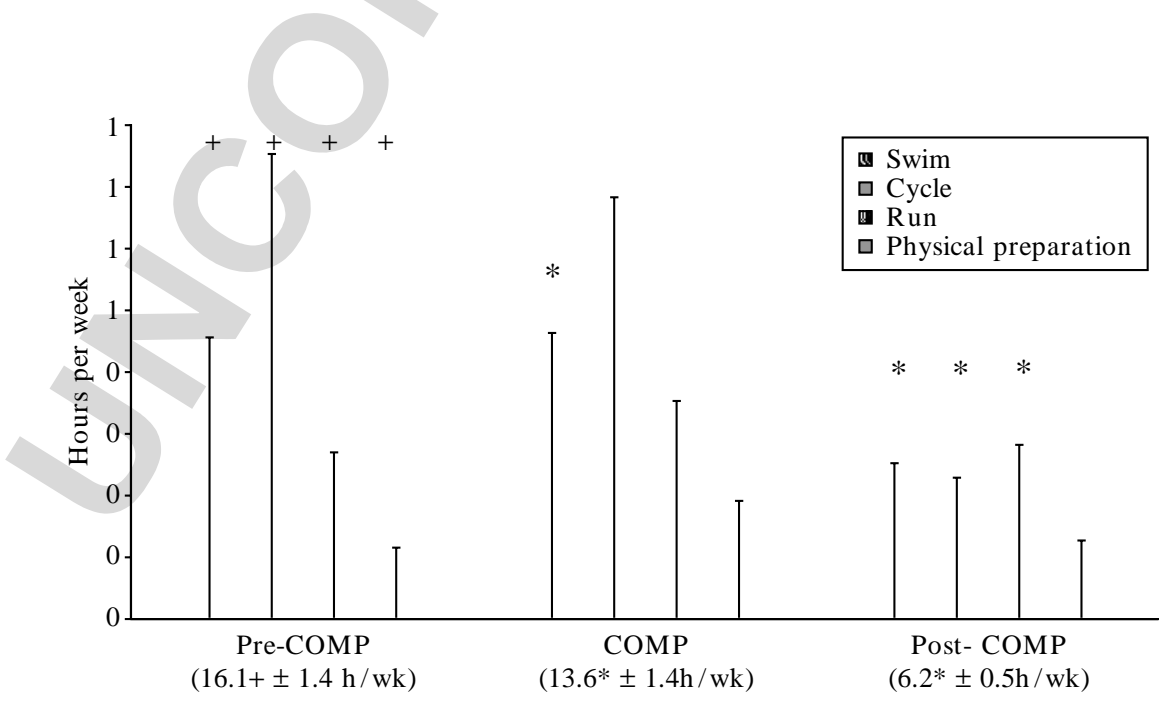

q1 Fig. 1. 
Maximal $\mathrm{O}_{2}$ uptake and power during a season in triathletes

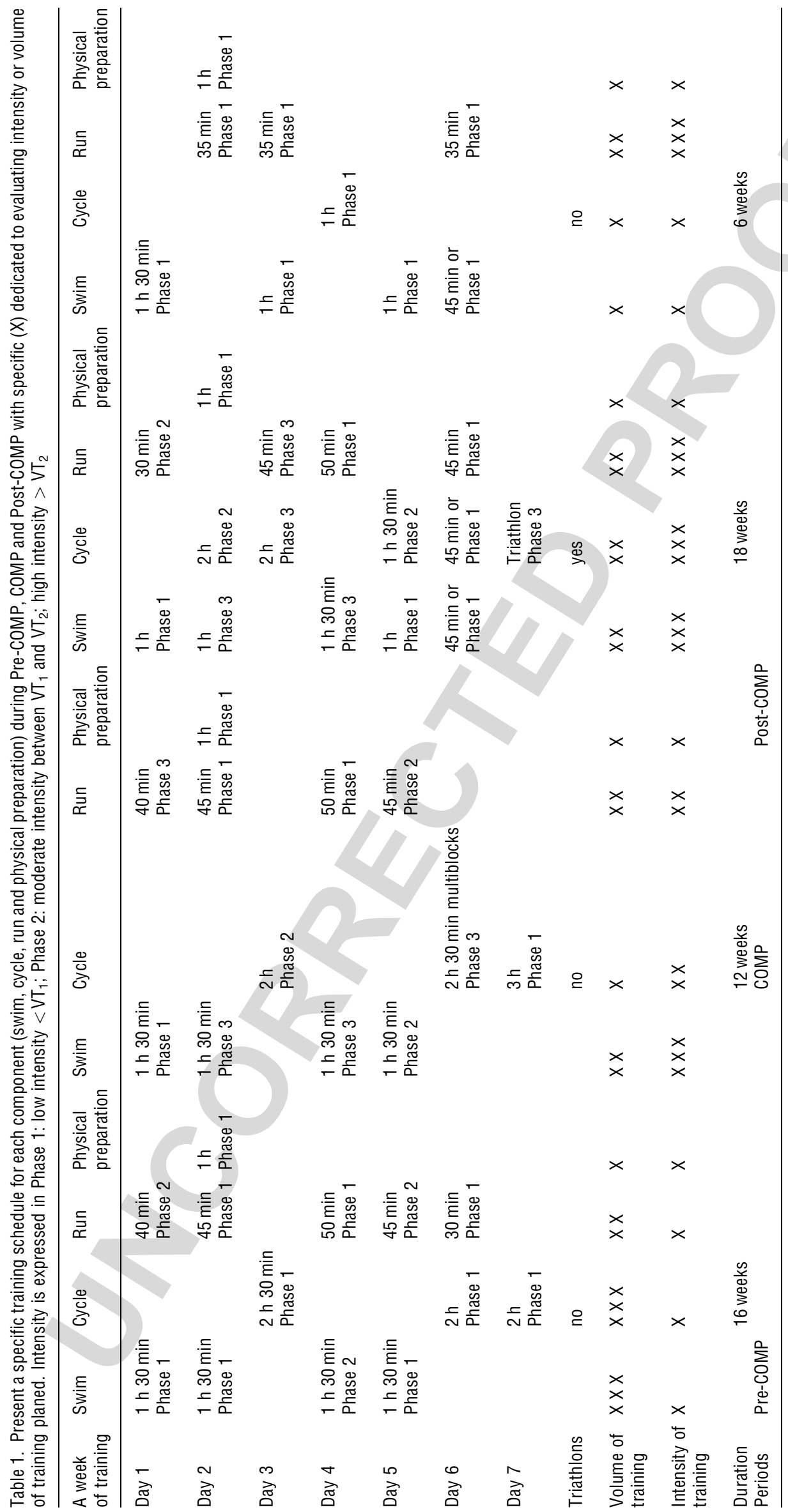




\section{Galy et al.}

Maximal oxygen uptake test

After a recovery period of $45 \mathrm{~min}$, in which anthropometric measures and an ECG were done, the triathletes performed an incremental test on an electronically braked cycle ergometer (Orion, S.T.E, Toulouse, France) to measure their maximal oxygen uptake and aerobic power (AeP). After a 3-min warm-up period at $60 \mathrm{~W}$, power was increased by $30 \mathrm{~W}$ every minute until the subject reached volitional fatigue. Pedalling speed remained constant (72 r.p.m) throughout the test. All triathletes reached their maximal oxygen uptake with: (1) a leveling-off of $\mathrm{VO}_{2}$ despite increasing load (2) respiratory exchange ratio (RER) greater than 1.10 (3) attainment of age-predicted maximal heart rate (HR) $\pm 5 \%(210-(0.65$ age $))$, and (4) the inability of the subject to maintain pedalling frequency despite maximum effort and verbal encouragement.

\section{Gas exchange measurements}

The measuring instruments were calibrated before each test and ventilatory data were computed every minute using an automatic gas analyzer (CPX analyzer, Medical Graphics Corporation, Saint-Paul, $\mathrm{MN})$ : minute ventilation $\left(\mathrm{V}_{\mathrm{E}}\right)$, oxygen uptake $\left(\mathrm{VO}_{2}\right)$, carbon dioxide production $\left(\mathrm{V} \mathrm{CO}_{2}\right)$, respiratory exchange ratio (RER), respiratory equivalents for $\mathrm{O}_{2}\left(\mathrm{~V}_{\mathrm{E}} / \mathrm{VO}_{2}\right)$ and $\mathrm{CO}_{2}$ $\left(\mathrm{V}_{\mathrm{E}} / \mathrm{V} \mathrm{CO}_{2}\right)$, respiratory rate $(\mathrm{RR})$, and tidal volume $(\mathrm{VT})$. Heart rate (HR) was measured using a telemetry system (Polar Vantage NV, Polar Electro Oy, Kempele, Finland). The two ventilatory thresholds $\left(\mathrm{VT}_{1}\right.$ and $\left.\mathrm{VT}_{2}\right)$ were determined visually by two investigators, using a double-blind procedure. Both were defined from the time course curves of $\mathrm{V}_{\mathrm{E}}$ and the ventilatory equivalents of $\mathrm{O}_{2}$ and $\mathrm{CO}_{2}$. The first ventilatory threshold, $\mathrm{VT}_{1}$, was determined by a non-linear increase in $\mathrm{V}_{\mathrm{E}}$ and $\mathrm{V}_{\mathrm{E}} / \mathrm{VO}_{2}$, without any increase in $\mathrm{V}_{\mathrm{E}} / \mathrm{VCO}_{2}$ (Wasserman, Whipp, Casaburi, 1986). The second ventilatory threshold, $\mathrm{VT}_{2}$, was identified by the second nonlinear increase in $\mathrm{V}_{\mathrm{E}}$ and $\mathrm{V}_{\mathrm{E}} / \mathrm{VO}_{2}$ accompanied by a concomitant non-linear increase in $\mathrm{V}_{\mathrm{E}} / \mathrm{VCO}_{2}$ (Ahmaidi, Hardy, Varray, Collomp, Mercier, Préfaut, 1993). Thresholds were expressed in terms of percentage of $\mathrm{VO}_{2}$.

\section{Statistical analysis}

The results were expressed as means \pm SEM. After verification of a normal distribution (Gaussian graphical distribution), the physical and maximal data, hours of training, AeP, AnP and cardioventilatory data $\left(\mathrm{VO}_{2}, \mathrm{~V} \mathrm{HR}, \mathrm{VT}_{1}\right.$, and $\left.\mathrm{VT}_{2}\right)$ recorded throughout the incremental test were compared using a oneway analysis of variance (ANOVA) with repeated measures. When significant results were obtained with ANOVA, posthoc comparisons were made using Scheffe's posthoc test. Pearson product moment correlations were used to compare relationships between variables. Statistical analysis was performed using a computerized statistical software package (SYSTAT). Statistical significance was accepted at the $P<0.05$ level.

\section{Results}

Training

The kinetics of the total training hours showed significant differences between periods $(P<0.001)$. Swim, cycle, run and physical preparation training were significantly lower in Post-COMP as compared with Pre-COMP $\left(P<10^{-4}\right.$, fig. 1). Swim training was significantly higher in Pre-COMP compared with $\operatorname{COMP}(P<0.03$, fig. 1$)$. Swim, cycle, and run training were significantly higher in COMP compared with
Post-COMP $\left(P<10^{-2}, P<10^{-4}, P<10^{-4}\right.$, respectively, fig. 1).

\section{Aerobic power and cardioventilatory responses to incremental exercise}

At $\mathrm{VT}_{1}$ significantly different power values were observed in the three periods $(P<0.02$; Table 2$)$. In addition, as shown in Table 2, a significantly lower power was observed in Post-COMP when compared with Pre-COMP $(P<0.05)$ and COMP $\left(P<10^{-2}\right)$.

At $\mathrm{VT}_{2}$ significantly different $\mathrm{O}_{2}$ consumption, heart rate and power values were observed in the three periods $\left(P<10^{-4}, P<10^{-4}\right.$ and $P<10^{-4}$, respectively; Table 2). In addition, significantly lower $\mathrm{O}_{2}$ consumption, HR and power at $\mathrm{VT}_{2}$ were observed in PostCOMP when compared with both Pre-COMP $\left(P<10^{-3}, \quad P<10^{-2}\right.$ and $P<10^{-4}$; Table 2) and COMP $\left(P<10^{-3}, P<10^{-2}\right.$ and $P<10^{-4}$; Table 2$)$.

At maximal exercise significantly different maximal power values were observed in the three periods $\left(P<10^{-3} ;\right.$ fig. 2$)$. In addition, as shown in Table 2 , a significantly lower AeP was observed in Post-COMP compared with Pre-COMP $\left(P<10^{-3}\right)$ and COMP $(P<0.003)$.

\section{Maximal performance obtained with CMJ}

Figure 2 shows a significant difference among the three periods $(P<0.008)$. Moreover, a significant decrease in AnP was observed between Pre-COMP and COMP $(P<0.03)$, and a significant increase was noted between COMP and Post-COMP $(P<0.02)$.

\section{Correlations}

Figure 3 shows a significant inverse correlation between total training hours (cycle and run) and AnP $(r=-0.832 ; P<0.01$; fig. 3$)$ at Post-COMP. Moreover, at Post-COMP we noted a significant inverse correlation between running training hours and AnP $(r=-0.810 ; P<0.01)$ and a significant inverse correlation between cycling training hours and $\operatorname{AnP}(r=-0.771 ; P<0.02)$.

\section{Discussion and conclusions}

The main findings of the present study were (1) the stability of maximal $\mathrm{O}_{2}$ uptake throughout the entire triathlon training season independent of both training volume and training intensity, and (2) the decrease in anaerobic performance at the end of the competitive period. Furthermore, the $\mathrm{VT}_{2}$ as well as the power output at $\mathrm{VT}_{1}$ and $\mathrm{VT}_{2}$, and AeP were significantly decreased after the postcompetitive period.

From a methodological point of view, we chose to assess $\mathrm{VO}_{2 \max }$ on a cycle ergometer based on the recent 
Table 2. Cardioventilatory and power parameters measured at rest, $\mathrm{VT}_{1}, \mathrm{VT}_{2}$, and maximal exercise during Pre-COMP,COMP and Post-COMP. * Significantly different from Post-COMP, $P<0.05$. Values are means \pm SEM

\begin{tabular}{|c|c|c|c|c|c|c|}
\hline & \multicolumn{2}{|l|}{$\begin{array}{l}\mathrm{VO}_{2} \\
\left(\mathrm{I}_{\mathrm{min}}^{-1}\right)\end{array}$} & \multicolumn{4}{|c|}{$\begin{array}{l}\mathrm{VO}_{2} \\
\left(\mathrm{ml} \cdot \min \cdot \mathrm{kg}^{-1}\right)\end{array}$} \\
\hline & Pre-COMP & COMP & Post-COMP & Pre-COMP & COMP & Post-COMP \\
\hline Rest & 0.5 & 0.4 & 0.4 & 8.7 & 7.0 & 6.5 \\
\hline 0.0 & 0.0 & 0.0 & 0.5 & 0.9 & 0.5 & \\
\hline $\mathrm{VT}_{1}$ & 2.7 & 2.7 & 2.5 & 41.3 & 40.6 & 37.3 \\
\hline 0.1 & 0.1 & 0.2 & 2.6 & 2.2 & 3.6 & \\
\hline$\%$ & 74.0 & 73.8 & 75.6 & 70.4 & 65.5 & 59.4 \\
\hline 0.2 & 0.2 & 0.2 & 5.0 & 1.9 & 4.0 & \\
\hline $\mathrm{VT}_{2}$ & $3.69^{*}$ & $3.67^{\star}$ & 3.3 & $55.8^{*}$ & $55.4^{*}$ & 49.0 \\
\hline 0.21 & 0.2 & 0.2 & 2.8 & 3.3 & 4.1 & \\
\hline$\%$ & $88.9^{*}$ & $88.6^{\star}$ & 79.0 & $90.4^{*}$ & $89.0^{*}$ & 78.3 \\
\hline 0.2 & 0.2 & 0.2 & 1.9 & 1.5 & 4.2 & \\
\hline \multirow[t]{4}{*}{$\operatorname{Max}$} & 4.15 & 4.14 & 4.2 & 62.7 & 62.0 & 62.1 \\
\hline & 0.2 & 0.19 & 0.2 & 2.5 & 3.0 & 3.3 \\
\hline & \multicolumn{3}{|c|}{$\begin{array}{l}\text { HR } \\
\text { (beats. } \min ^{-1} \text { ) }\end{array}$} & \multicolumn{3}{|l|}{$\begin{array}{l}\text { Power } \\
\text { (W) }\end{array}$} \\
\hline & Pre-COMP & COMP & Post-COMP & Pre-COMP & COMP & Post-COMP \\
\hline Rest & 67.0 & 65.8 & 69.5 & & & \\
\hline 4.2 & 4.7 & 3.4 & & & & \\
\hline $\mathrm{VT}_{1}$ & 141.3 & 144.3 & 138.3 & $251.2^{\star}$ & $247.5^{\star}$ & 198.7 \\
\hline 4.0 & 2.9 & 3.7 & 21.1 & 17.7 & 17.8 & \\
\hline$\%$ & 79.2 & 79.1 & 75.7 & $64.2^{\star}$ & $64.5^{\star}$ & 54.6 \\
\hline 2.0 & 1.3 & 2.7 & 3.7 & 3.3 & 3.9 & \\
\hline $\mathrm{VT}_{2}$ & $169.6^{*}$ & $170.0^{*}$ & 160.3 & $371.2^{*}$ & $341.2^{*}$ & 281.2 \\
\hline 2.2 & 3.1 & 4.1 & 17.8 & 22.6 & 22.6 & \\
\hline$\%$ & $95.0^{\star}$ & $93.1^{\star}$ & 87.8 & $95.1^{*}$ & $88.7^{\star}$ & 56.3 \\
\hline 0.6 & 0.7 & 2.3 & 1.4 & 2.7 & 3.9 & \\
\hline \multirow[t]{2}{*}{$\operatorname{Max}$} & 178.3 & 182.6 & 182.8 & $390.0^{*}$ & $382.5^{\star}$ & 360.0 \\
\hline & 1.8 & 2.7 & 2.8 & 17.9 & 16.7 & 16.0 \\
\hline
\end{tabular}

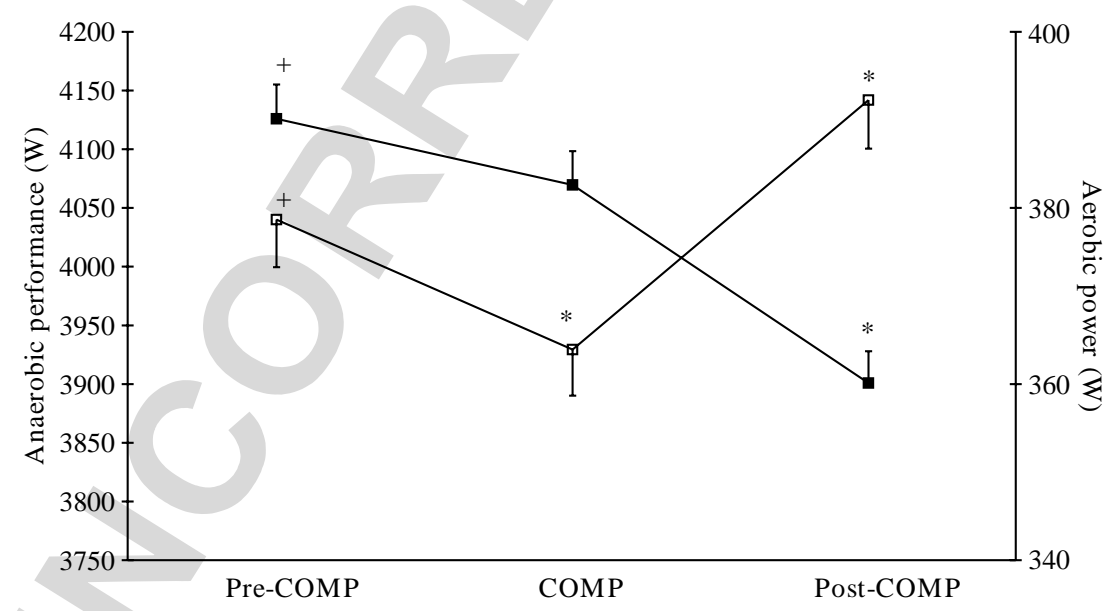

Fig. 2.

study of Hue et al. (2000), who showed similar $\mathrm{VO}_{2 \max }$ in young triathletes with treadmill and cycle ergometer testing. The authors demonstrated that these triathletes, without prior athletic specialization, probably developed similar $\mathrm{VO}_{2 \max }$ with both ergometers because of the cross-training effects of each discipline (i.e., cycling and running). Although most studies have explored anaerobic performance using the forcevelocity (FV) test (Obert, Mandigout, Vinet, Courteix, 2001) or the Wingate test (Bar-Or 1987), some have investigated the effect of strength training on shortdistance running performance using a five-jump test 


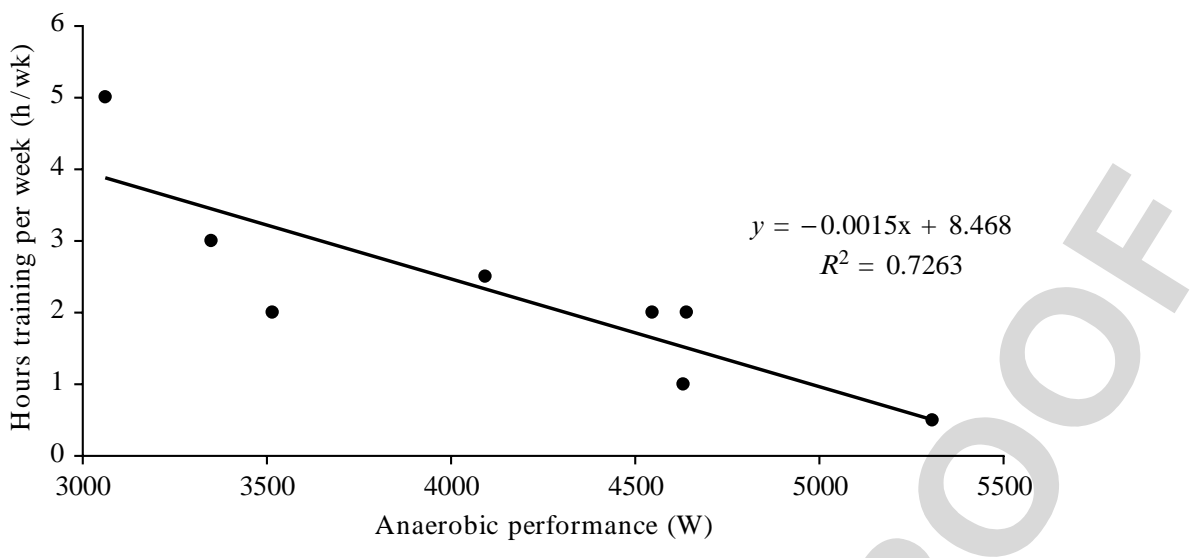

Fig. 3.

(Paavolainen et al., 1999) or after long distance running (2 h) using a CMJ (Lepers et al., 2000b). Moreover, the maximal $\mathrm{CMJ}$ is correlated with maximal anaerobic power as noted on a Monark ergometer (Vandewalle et al., 1987) and has been demonstrated to be the anaerobic performance best correlated to the different kinematic parameters of the run (Hoffman \& Kang, 2002). Moreover, significant correlations have been demonstrated between peak torque on a 'Cybex' isokinetic ergometer and different jump tests (Bosco, Komi, Tihanyi, Fekete, Agor, 1983). Jones et al. (1985) noted that the energy required during fastspeed cycling was issued from instantly available ATP in muscle, the phosphocreatine system, and anaerobic glycolysis. Therefore, in spite of the brevity of each exercise bout, the anaerobic metabolism involved during both the FV and Wingate tests must be considered as both alactic and lactic anaerobic metabolism (Jones et al., 1985). In the present study, the jump-andreach test was a maximal, extremely brief exercise that has been demonstrated to be an alactic anaerobic test (Davies \& Young, 1984; Hertogh, Micallef, Mercier, 1992). The results of the present study, however, suggest some limitations. The $\mathrm{CMJ}$ is performed according to a variety of techniques (Van Zandwiijk, Bobbert, Munneke, Pas, 2000), and it does not depend exclusively on maximal power, but also on the stretch reflex and neuromuscular coordination (Van Zandwiijk et al., 2000). Both the magnitude and the rapidity of the countermovement contribute to vertical jump performance, and the variation in these factors contributes to error in maximal power prediction (Van Zandwiijk et al., 2000). However, as each triathlete was compared to himself, we may assume that differences in jump technique would not have impaired CMJ measurements. Therefore, we cannot exclude the possibility that factors other than estimated power, such as the stretch reflex or neuromuscular co-ordination, were responsible for the difference in $\mathrm{CMJ}$ performance.

The present results show that during the entire competitive season (Pre-COMP, COMP, and Post-COMP), no differences in $\mathrm{VO}_{2 \max }$ were observed between periods. This may be explained by the continuous (but different) training pattern followed throughout the year and described in fig. 1 and Table 1. One to two weeks before the COMP tests, the triathletes participated in the French Triathlon Championship, which was considered as the major objective of the competitive season. The whole training schedule was thus organized around this key event. When such an event is placed at the end of the competitive season, highly trained triathletes often partially stop their intensive training and take a 'break' from competition, here called Post-COMP, for about six weeks. These six weeks appeared to be too short to reduce significantly the $\mathrm{VO}_{2 \max }$ and this finding reinforces the concept of cross-training effects suggested in triathletes (Hue et al., 2000; Millet et al., 2002). This is particularly so because of the significantly different cycling training volume (expressed in $\mathrm{h} /$ week) between the entire COMP and the Post-COMP periods (fig. 1). The transfers of training influences between different disciplines have been extensively studied and reviewed (Tanaka, 1994). The reduced training schedule during six weeks, with lower volume and intensity in each activity, resulted in a significantly lower $\mathrm{AeP}$ at $\mathrm{VO}_{2 \max }$ accompanied by a lower $\mathrm{VT}_{2}$ at the end of Post-COMP, compared with Pre-COMP and COMP (Table 2). At the same intensity, two parameters significantly decreased: the power and HR responses. First, the power (at both $\mathrm{VO}_{2 \max }$ and $\mathrm{VT}_{2}$ ) decrease might be explained by the large reduction in cycling training (from $5.3 \pm 0.6 \mathrm{~h}$ / wk $-1.5 \pm 0.1 \mathrm{~h} / \mathrm{wk}^{-1}$ ) during Post-COMP. Bentley, Wilson, Davie and Zhou (1998) showed that AeP is a reliable variable to assess cycling performance in triathletes, confirming the reduced intensity of their training as shown by the lower $\mathrm{VT}_{2}$ during the period. In spite of cross-effects, which have been shown between cycling and running (Hue et al., 2000; Millet et al., 2002), we could also suggest that reduced mitochondrial and capillary densities due to cycling training (Åstrand \& Saltin, 1961; Saltin, 1977) were responsible for the 
diminished power during Post-COMP. Next, the significant decrease in $\mathrm{HR}$ at $\mathrm{VT}_{2}$ seemed surprising. Usually if the power or $\mathrm{VO}_{2}$ decreases at $\mathrm{VT}_{1}$ or $\mathrm{VT}_{2}$, the heart rate remains at the same level, signifying that the athlete can do less work at the same heart rate during a sub-maximal exercise. But in the present study both AeP and HR decreased, which means that the athletes could do the same work at the same HR. This could also be explained by their sub-maximal endurance capacity, which did not change between periods (Coyle \& Martin, 1985). After Post-COMP, an increased reliance on carbohydrate metabolism during exercise probably resulted from a reduced insulin sensitivity and GLUT-4 transporter protein content, coupled with a lowered muscle lipoprotein lipase activity for a lower percentage of $\mathrm{V} \mathrm{VO}_{2 \max }$ and consequently accompanied by lower HR values (Mujika \& Padilla, 2001). Lucia, Hyos, Peres, Chicharro (2000), in a similar longitudinal study in elite cyclists, observed no changes in either maximal $\mathrm{O}_{2}$ uptake or physiological markers of performance including $\mathrm{VT}_{1}, \mathrm{VT}_{2}$ and lactate threshold between three different periods of training corresponding to a pre-competition period, a competition period and an active 'rest' period of two to three weeks. Although no changes in maximal $\mathrm{O}_{2}$ uptake were observed throughout the whole triathlon competitive season, we assume that six weeks of low training was too long for highly trained triathletes to preserve their aerobic adaptations to training. The specific exercise (i.e., cycling) and/or the duration of the 'break' period was probably responsible for reduced muscular and cardiovascular adaptations at sub-maximal exercise, whereas only reduced muscular adaptations at maximal exercise were observed.

The results of the present study concerning anaerobic performance are quite surprising. At nearly the end of the COMP period, one to two weeks after the French Triathlon Championship, we observed a greatly diminished AnP, which may have limited running performance, as already demonstrated in athletes (Noakes 1988; Paavolainen et al., 1999). Avela, Kyrolainen, Komi, Rama (1999) demonstrated that six days after a marathon the impact time was both longer and lower in stretch-shortening cycle exercise compared to similar pre-marathon tests. Because the tests were conducted one to two weeks after the race, we cannot rule out that the race affected the CMJ results. However, the running distance of a marathon is approximately four times the triathlon running distance and even if it impacted the CMJ results, this would not totally explain the present data. One explanation could be the volume and intensity of training. The triathletes of the present study had high training volume and the effects of prolonged exercise such as running and cycling has been demonstrated to decrease muscular strength (Nicol, Komi, Marconnet, 1991; Lepers et al., 2000a,b). One could assume that when we compared both Pre-COMP and COMP to Post-COMP, the daily multi-training would have influenced muscle strength to decrease anaerobic performance as measured by the $\mathrm{CMJ}$. However, because the training volume was higher during Pre-COMP than during COMP, this reasoning cannot be used. During COMP, only swimming volume was significantly reduced, whereas the intensity was substantially increased in each event (Table 1). As both prolonged (Nicol et al., 1991) and short-term intensive exercises (Nummela, Rusko, Mero 1994) induce a decrease in force-generating capacity, one could assume that the combination of high volume and high intensity significantly reduced anaerobic performance during COMP. At Post-COMP, after six weeks of low training, an inverse correlation was found between total training hours (cycle and run) and $\operatorname{AnP}(r=-0.832 ; P<0.01$, fig. 3$)$ and, in addition, significant inverse relations were found between running training hours and $\mathrm{AnP}(r=-0.810 ; P<0.01)$ and between cycling training hours and AnP $(r=-0.771$; $P<0.02$ ), while no relations were found during the other periods. All these correlations suggest a deleterious effect of both high volume and high intensity on AnP. Another explanation could be the repeated competitions during the 18 weeks of the competitive period (with $10 \pm 1.3$ triathlons performed). These repeated competitions may have affected the neuromuscular system, which has already been demonstrated in marathon runners (Avela et al., 1999) and is perhaps here indicated by a significant reduction in anaerobic performance. This observation needs to be more fully explored, but we can raise the question of wasted benefits of training programs, mainly during the specific period of competition in which triathletes must turn in their best performances.

\section{Perspectives}

The findings of the present study showed no change in maximal $\mathrm{O}_{2}$ uptake throughout the season, but AnP was decreased after the COMP period. Despite the primary importance of $\mathrm{AeP}$ and maximal $\mathrm{O}_{2}$ uptake during endurance activities, anaerobic performance can improve overall performance during running in highly trained athletes (Noakes, 1988; Paavolainen et al., 1999). Thus, it might be interesting to more fully explore (1) the role of the anaerobic metabolism in triathletes and specifically in terms of their training, and (2) the value of specific explosive strength training simultaneously with endurance training in triathletes to evaluate its benefits.

\section{Conclusions}

In summary, this study showed stable maximal $\mathrm{O}_{2}$ uptake throughout an entire triathlon season that was 


\section{Galy et al.}

independent of training volume and intensity, while $\mathrm{AeP}, \mathrm{VT}_{2}$ and power output at $\mathrm{VT}_{1}$ and $\mathrm{VT}_{2}$ decreased after the Post-COMP period. This suggests that six weeks of low training seems to be too long for highly trained triathletes to preserve their physiological adaptations to training. In addition, AnP decreases after the competitive period of the season, suggesting that specific explosive strength training simultaneously with endurance training should be tested in triathletes to evaluate the benefits of such a method on running performance in the triathlon.
Key words: $\mathrm{VO}_{2 \max }$; ventilatory thresholds; maximal aerobic power; parameters of performance; training; triathlon.

\section{Acknowledgements}

We wish to acknowledge the Center Régional d'Education Populaire et Sportif de Montpellier, France, for their financial and technical support. Thanks to the Ligue LanguedocRoussillon de Triathlon et Duathlon, 34200 Sète, France. We especially thank the triathletes for their cooperation.

\section{References}

Ahmaidi SJ, Hardy JM, Varray A, Collomp K, Mercier J, Préfaut C. Respiratory gas exchange indices used to detect the blood lactate accumulation threshold during an incremental exercise test in young athletes. Eur $\mathbf{J} \mathrm{Appl}$ Physio1 1993: 66: 31-36.

Åstrand PO, Saltin B. Maximal oxygen uptake and heart rate in various types of muscular activity. J Appl Physiol 1961: 16: 977-981.

Avela J, Kyrolainen H, Komi PV, Rama D. Reduced reflex sensitivity persists several days after long-lasting stretch-shortening cycle exercise. J Appl Physiol 1999: 86 (4): 1292-1300.

Bar Or O. The Wingate anaerobic test. An update on methodology, reliability and validity. Sports Med 1987: 4(6): 381-394.

Bentley DJ, Wilson GJ, Davie AJ, Zhou S. Correlations between maximal power output, muscular strength and cycle time trial performance in triathletes. J Sports Med Phys Fitness 1998: 38(3): 201-207.

Billat LV, Koralsztein JP. Significance of the velocity at $\mathrm{VO}_{2 \max }$ and time to exhaustion at this velocity. Sports Med 1996: 22: 90-108.

Bosco C, Komi PV, Tihanyi J, Fekete G, Agor P. Mechanical power test and fiber composition of human leg extensor muscles. Eur J Appl Physiol 1983: 51: 129-135.

Conley DL, Krahenbuhl GS. Running economy and distance running performance of highly trained athletes. Med Sci Sports Exerc 1980: 12: 357-360.

Coyle EF, Martin WH 3rd, Bloomfield SA, Lowry OH, Holloszy JO. Effects of detraining on responses to sub-maximal exercise. J Appl Physiol 1985: 59: 853-859.

Davies CTM, Young K. Effects of external loading on short-term power output in children and young male adults. Eur J Appl Physiol 1984: 52: 351-354.

Hausswirth C, Bigard AX, Guezennec CY. Relationship between running mechanics and energy cost of running at the end of a triathlon and a marathon. Int J Sports Med 1997: 18: 330-339.

Hertogh C, Micallef JP, Mercier J. Maximal anaerobic power in teenagers (transversal study). (Puissance anaérobie maximale chez l'adolescent). Sci Sports 1992: 7: 207-213.

Hoffman JR, Kang J. Evaluation of a new anaerobic power testing system. J Strength Cond Res 2002: 16(1): 142-148.

Hue O, Le Gallais D, Boussana A, Chollet $D$, Préfaut C. Ventilatory threshold and maximal oxygen uptake in present triathletes. Can J Appl Physiol 2000: 25: 102-113.

Hue O, Le Gallais D, Chollet D, Boussana A, Préfaut C. The influence of prior cycling on biomechanical and cardiorespiratory response profiles during running in triathletes. Eur J Appl Physiol 1998: 77: 98-105.

Jones NL, McCartney N, Graham T, et al. Muscle performance and metabolism in maximal isokinetic cycling et slow and fast speed. J Appl Physiol 1985: 59: 132-136.

Kohrt WM, Morgan DW, Bates B, Skinner JS. Physiological responses of triathletes to maximal swimming, cycling and running. Med Sci Sports Exerc 1987: 19 (1): 51-55.

Kreider RB. Ventilatory threshold in swimming, cycling and running in triathletes. Int J Sports Med 1988: 9: 147-148.

Laurenson NM, Fulcher KY, Korkia P. Physiological characteristics of elite and club level female triathletes during running. Int J Sports Med 1993: 14(8): 455-459.

Lepers R, Hausswirth C, Maffiuletti N, Brisswalter J, Van Hoecke J. Evidence of neuromuscular fatigue after prolonged cycling exercise. Med Sci Sports Exerc 2000a: 32(11): 1880-1886.

Lepers R, Pousson ML, Maffiuletti NA, Martin A, Van Hoecke J. The effects of a prolonged running exercise on strength characteristics. Int J Sports Med 2000b: 21(4): 275-280.

Lucia A, Hoyos J, Perez M, Chicharro JL. Heart rate and performance parameters in elite cyclists: a longitudinal study. Med Sci Sports Exerc 2000: 32(10): 1777-1782.

Millet GP, Candau RB, Barbier B, Busso T, Rouillon JD, Chatard JC. Modeling the transfers of training effects on performance in elite triathletes. Int J Sports Med 2002: 23: 55-63.

Millet GP, Millet GY, Hofmann MD, Candau RB. Alterations in running economy and mechanics after maximal cycling in triathletes: influence of performance level. Int J Sports Med 2000: 21(2): 127-132.

Morgan DW, Martin PE, Krahenbuhl GS Factors affecting running economy. Sports Med 1898: 7: 310-330.

Mujika I, Padilla S. Cardiorespiratory and metabolic characteristics of detraining in humans. Med Sci Sports Exerc 2001: 33: 413-421.

Nicol C, Komi PV, Marconnet P. Fatigue effects of marathon running on neuromuscular performance. II. Changes in force, integrated electromyographic activity and endurance capacity. Scand J Med Sci Sports 1991: 1: 18-24.

Noakes TD. Implications of exercise testing for prediction of athletic performance: a contemporary perspective. Med Sci Sports Exerc 1988: 20: 319-330.

Noakes TD, Myburgh KH, Schall R. Peak treadmill running velocity during the $\mathrm{VO}_{2}$ max test predicts running performance. J Sports Sci 1990: 8: 35-45.

Nummela A, Rusko H, Mero A. EMG activities and ground reaction forces during fatigued and non-fatigued sprinting. Med Sci Sports Exerc 1994: 26 (5): 605-609.

Obert P, Mandigout M, Vinet A, Courteix D. Effect of a 13-week aerobic training programme on the maximal power 


\section{Maximal $\mathrm{O}_{2}$ uptake and power during a season in triathletes}

developed during a force-velocity test in pre-pubertal boys and girls. Int J Sports Med 2001: 22(6): 442-446.

Paavolainen L, Häkkinen K, Hämäläinen I, Nummela A, Rusko H. Explosivestrength training improves 5-km running time by improving running economy and muscle power. J Appl Physiol 1999: 86 (5): 1527-1533.

Roalstad MS. Physiologic testing of the ultra-endurance triathlete. Med Sci Sports Exerc 1989: 21: 200-204.

Saltin B. The interplay between peripheral and central factors in the adaptative response to exercise and training. Ann NY Acad Sci 1977: 301: 224-227.

Sayers SP, Harackiewicz VD, Harman EA, Frykman PN, Rosenstein MT. Crossvalidation of three jump power equations. Med Sci Sports Exerc 1999: 31 (4): $572-577$.

Skinner JS, McLellian TH. The transition from aerobic to anaerobic metabolism. Res Q Exerc Sport 1980: 51: 234-238.

Tanaka H. Effects of cross-trainingtransfer of training effects on $\mathrm{VO}_{2 \max }$ between cycling, running and swimming. Sports Med 1994: 18: 330-339.
Van Zandwiijk JP, Bobbert MF, Munneke M, Pas P. Control of maximal and sub-maximal vertical jumps. Med Sci Sports Exerc 2000: 32: 477-485.

Vandewalle H, Peres G, Monod H. Standard anaerobic exercise tests. Sports Med 1987: 4: 268-289.

Wassermann K, Whipp BJ, Casaburi R. Respiratory control during exercise. Handbook Physiol 1986: 17: 595-619. 


\section{Author Query Form}

\section{Journal: Medicine \& Science in Sports}

Article: 10170

Dear Author,

During the copy-editing of your paper, the following queries arose. Please respond to these by marking up your proofs with the necessary changes/additions. Please write your answers on the query sheet if there is insufficient space on the page proofs. Please write clearly and follow the conventions shown on the attached corrections sheet. If returning the proof by fax do not write too close to the paper's edge. Please remember that illegible mark-ups may delay publication.

\begin{tabular}{|l|l|l|}
\hline Query Refs. & Query & Remarks \\
\hline 1 & Au: Please provide Figure caption for Figs 1,2 and 3. & \\
\hline 2 & $\begin{array}{l}\text { Au: Fig 1. Figure labelling are not shown in fig, } \\
\text { please check. }\end{array}$ & \\
\hline
\end{tabular}

Typesetters Query:

Please provide accepted date. 


\section{MARKED PROOF}

\section{Please correct and return this set}

Any errors in this proof which have been noticed by the printer's reader have been marked in green. If you see any more printer's errors, please mark them in red: there is no charge for correcting these mistakes. For your own alterations, please use black or blue or any colour other than green or red. Please use the proof correction marks shown below for all alterations and corrections.

\begin{tabular}{|c|c|c|}
\hline Instruction to printer & Textual mark & Marginal mark \\
\hline Leave unchanged & $\cdots$ under matter to remain & Stet \\
\hline $\begin{array}{l}\text { Insert in text the matter } \\
\text { indicated in the margin }\end{array}$ & $h$ & New matter followed by \\
\hline Delete & $\mapsto$ through matter to be deleted & $\hat{\delta}$ \\
\hline Delete and close up & a through matter to be deleted & हो \\
\hline $\begin{array}{l}\text { Substitute character or } \\
\text { substitute part of one or } \\
\text { more word(s) }\end{array}$ & $\begin{array}{l}\text { / through letter or } \mapsto \text { through } \\
\text { word }\end{array}$ & New letter or new word \\
\hline Change to italics & - under matter to be changed & سب \\
\hline Change to capitals & $\equiv$ under matter to be changed & $\equiv$ \\
\hline Change to small capitals & $=$ under matter to be changed & $=$ \\
\hline Change to bold type & $\sim$ under matter to be changed & $m$ \\
\hline Change to bold italic & $\bar{\sim}$ under matter to be changed & 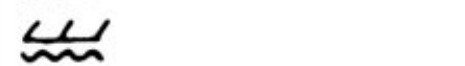 \\
\hline Change to lower case & Encircle matter to be changed & 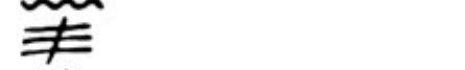 \\
\hline Change italic to upright type & (As above) & $\psi$ \\
\hline Insert 'superior' character & $\begin{array}{l}\text { I through character or } \wedge \text { where } \\
\text { required }\end{array}$ & $\begin{array}{l}y \text { under character } \\
\text { e.g. } y\end{array}$ \\
\hline Insert 'inferior' character & (As above) & $\boldsymbol{L}$ over character e.g. $\mathbf{L}$ \\
\hline Insert full stop & (As above) & $\odot$ \\
\hline Insert comma & (As above) & , \\
\hline Insert single quotation marks & (As above) & $\dot{y}$ and/or $\dot{y}$ \\
\hline $\begin{array}{l}\text { Insert double quotation } \\
\text { marks }\end{array}$ & (As above) & $\ddot{y}$ and/or $y$ \\
\hline Insert hyphen & (As above) & (ب) \\
\hline Start new paragraph & 5 & $\bar{\Gamma}$ \\
\hline No new paragraph & $\sim$ & $\sim$ \\
\hline Transpose & 凹 & $\sqrt{-1}$ \\
\hline Close up & linking $\approx$ letters & $=$ \\
\hline Insert space between letters & $h$ between letters affected & \# \\
\hline Insert space between words & $\boldsymbol{h}$ between words affected & \# \\
\hline Reduce space between letters & $\uparrow$ between letters affected & $T$ \\
\hline Reduce space between words & $\tau$ between words affected & $T$ \\
\hline
\end{tabular}

